\title{
Deteksi Mata Mengantuk Pada Pengemudi Mobil Menggunakan Metode Viola Jones
}

\author{
Imanuddin $^{1}$, Rahmat Maulana ${ }^{2}$, Munawir $^{3}$ \\ 1imannuddin2096@gmail.com, ${ }^{2}$ rahmatmaulana012@gmail.com ${ }^{3}$ munawir.@unsam.ac.id
}

Fakultas Teknik Universits Samudra, Kota Langsa

\begin{abstract}
More and more face detection and recognition systems. Although more and more, it does not mean that research on this subject has been completed. Demands for effectiveness, both speed and level of accuracy in a detection system are increasingly taken into account. Many of the several face detection systems use the Viola Jones method as an object detection method. The Viola Jones method is known to have high speed and accuracy because it combines several concepts (Haar Features, Integral Image, AdaBoost, and Cascade Classifier) into a main method for detecting objects. The programming language used in this paper uses the matlab programming language to make it easier to make the system. This paper aims to implement Viola Jones into a simple sleep eye detection system by utilizing the library in Matlab. After the system is completed, the system tests the detection characteristics of detectable drowsiness. This sleepy eye detection aims to determine whether the driver of the car is sleepy or not when driving with input in the form of eye detection taken using a digital camera and then inserted into a Matlab GUI programming language where binary and drowsy eyes are taken as a reference later it will be processed so as to produce output in the form of sound warning of the driver of the vehicle drowsy or not automatically.
\end{abstract}

Intisari --- Sistem pendeteksian dan pengenalan wajah semakin banyak. Walaupun semakin banyak, bukan berarti penelitian mengenai hal ini sudah selesai. Tuntutan akan efektifitas, baik kecepatan maupun tingkat keakuratan dalam sebuah sistem pendeteksian semakin diperhitungkan. Banyak dari beberapa sistem pendeteksian wajah menggunakan metode Viola Jones sebagai metode pendeteksi objek. Metode Viola Jones dikenal memiliki kecepatan dan keakuratan yang tinggi karena menggabungkan beberapa konsep (Haar Features, Integral Image, Ada Boost, dan Cascade Classifier) menjadi sebuah metode utama untuk mendeteksi objek. Bahasa pemrograman yang digunakan dalam makalah ini menggunakan bahasa pemrograman matlab sehingga memudahkan dalam pembuatan sistem. Makalah ini bertujuan untuk mengimplementasikan Viola Jones ke dalam sistem deteksi mata kantuk sederhana dengan memanfaatkan library yang ada pada matlab. Setelah sistem selesai dibuat, dilakukan pengujian sistem terhadap karakteristik deteksi mata kantuk yang dapat dideteksi.
Deteksi mata mengantuk ini bertujuan untuk menentukan apakah pengendara kendaraan mobil mengantuk atau tidak pada saat berkendara dengan input berupa deteksi mata yang diambil menggunakan kamera digital kemudian di masukkan ke dalam sebuah bahasa pemrograman GUI Matlab dimana diambil nilai mata biner mata mengantuk dan tidak mengantuk menjadi referensi yang nanti akan diolah sehingga menghasilkan output berupa suara peringatan pengendara kendara mobil mengantuk atau tidak secara otomatis.

\section{Kata Kunci : Komputer Vision, Mata Mengantuk, Viola Jones}

\section{PENDAHULUAN}

Di Indonesia, angka kecelakaan lalu lintas tiap tahun meningkat. Banyaknya kecelakaan disebabkan oleh berbagai faktor diantaranya faktor manusia, faktor kendaraan, dan faktor lingkungan [1]. Faktor kecelakaan yang disebabkan oleh manusia, Rasa kantuk saat berkendara adalah salah satu kondisi yang sering diabaikan oleh para pengendara bermobil dan merupakan salah satu penyebab sering terjadinya kecelakaan, terutama pada saat berkendara pada jarak yang cukup jauh [1][2]. Berdasarkan faktor di atas, maka kecelakaan kendaraan mobil dapat diminimalisir dengan adanya aplikasi deteksi mata mengantuk yang dipasang pada mobil [3] [4].

Pada mulanya mobil akan dipasangkan sebuah kamera berfungsi untuk mendeteksi mata. Kemudian kamera tersebut dihubungkan dengan laptop. Pada saat program dijalankan, maka pada saat pengendara mengalami kegantukan (mata mulai tertutup) maka alarm dari program deteksi mata akan berbunyi sehingga dengan frekuensi yang tinggi sehingga pengendara tersadarkan kembali.

Dengan adanya deteksi mata kantuk maka diharapkan akan mampu mengurangi tingkat kecelakaan yang sering terjadi akibat dari faktor kelalaian manusia dan dapat membantu mengawasi para pengendara kendara agar lebih waspada dengan kondisi yang ada [5] [6]. Berdasarkan permasalahan tersebut, maka penulis membuat suatu system "Deteksi Mata Mengantuk pada Pengendara Mobil Menggunakan Metode Viola Jones". 


\section{METODE PENELITIAN}

Metodologi penelitian merupakan cara yang digunakan untuk melakukan pengamatan dengan pemikiran yang tepat secara terpadu melalui tahapan-tahapan yang disusun secara ilmiah untuk mencari, menyusun serta menganalisis dan menyimpulkan data, sehingga dapat dipergunakan untuk menemukan, mengembangkan dan menguji kebenaran sesuai ilmu pengetahuan.

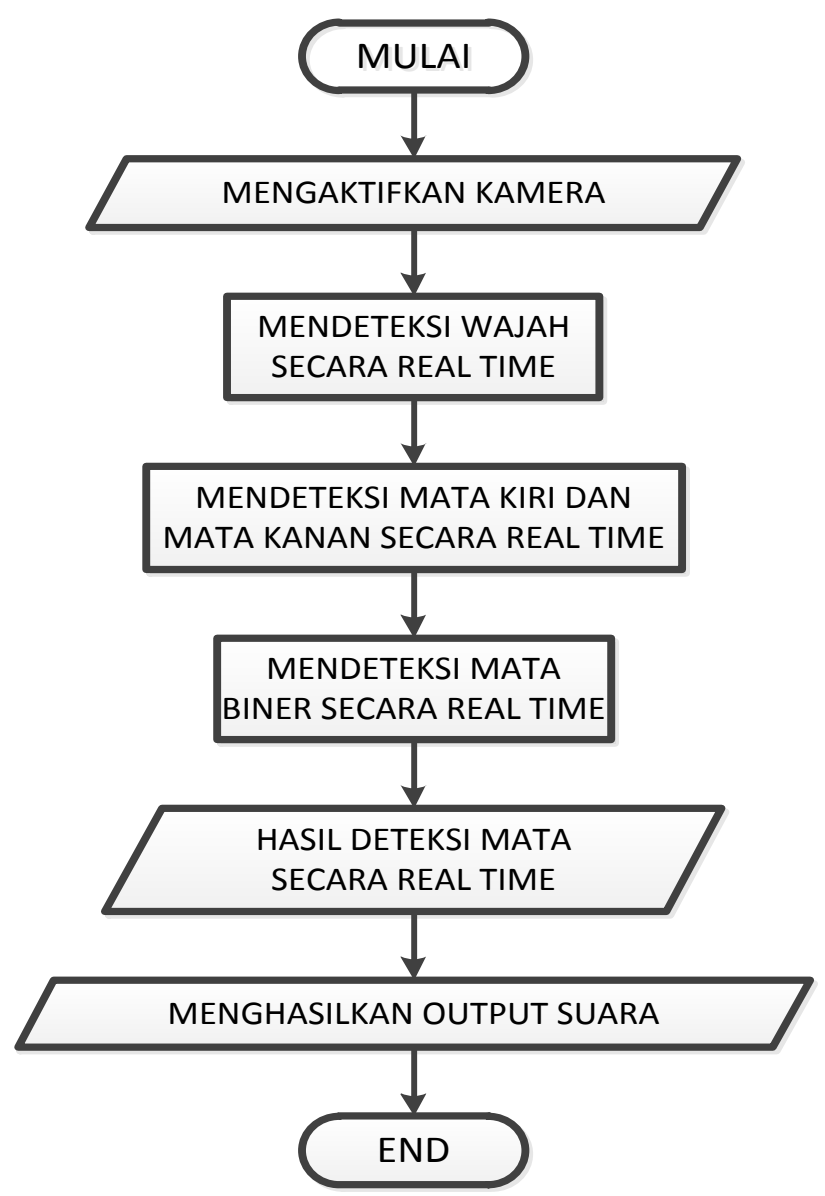

Gambar 3.1 Flowchart

\section{A. Menampilkan Gambar}

Proses pertama yaitu menangkap gambar secara realtime. Pada proses ini program akan terlebih dahulu mengatur resolasi agar gambar yang didapat berkualitas bagus jadi disarankan untuk menggunakan kamera Webcam atau kamera Output.

\section{B. Proses Mendeteksi Mata Biner}

Proses ini berfungsi untuk mendeteksi mata biner, mata biner ini yang nantinya digunakan untuk perhitungan apakah mata ngantuk atau tidak. jadi Mta Biner tersebut adalah suatu proses warna yang seperti hitam putih dan akan lebih cepat mendapatkan suatu nilai agar bisa mendeteksi bola mata kita dengan benar.

\section{Mendeteksi Mata tidak Mengantuk}

Proses ini berfungsi untuk mendeteksi mata biner, mata biner ini yang nantinya digunakan untuk perhitungan apakah mata ngantuk atau tidak. kalau program ini mendeteksi mata tidak mengantuk maka tidak akan mengeluarkan suara apapun dari program ini.

\section{Hasil deteksi mata yang mengantuk}

Pada proses ini aplikasi telah mendeteksi mata yang mengantuk yang ditandai dengan pemberitahuan pada menu bar yang berwarna merah dan pada proses ini alarm telah berbunyi sebagai peringatan bahwa mata telah mengantuk,yang mana suara alarm pemberitahuan tersebut dihasilkan dari suara music yang bisa kita ganti-ganti suaranya supaya menjadi unik dan lebih mudah mendengar suara alarm dari aplikasi mata mengantuk ini.

\section{HASIL DAN PEMBAHASAN}

\section{A. Implementasi Sistem}

Implementasi sistem Bertujuan untuk menjelaskan Tahapan - tahapan implementasi tersebut berupa implementasi perangkat lunak, implementasi perangkat keras dan hasil dari program aplikasi ini.

\section{B. Implementasi Perangkat Lunak}

Implementasi Perangkat Lunak merupakan Proses Instalasi perangkat Lunak, sehingga aplikasi bisa berjalan dengan Benar. Proses Instalasi Perangkat Lunak meliputi :

Tabel 4.2.1 Implementasi Perangkat Lunak

\begin{tabular}{|c|c|}
\hline Perangkat Lunak & Keterangan \\
\hline Microsoft Windows 7 Ultimate & Sistem Operasi \\
\hline Matlab R2015b & Aplikasi Pembangun \\
& System \\
\hline
\end{tabular}

\section{Implementasi Perangkat Keras}

Implemantasi perangkat keras merupakan realisasi dari analisis dan perancangan kebutuhan perangkat keras. Implementasi perangkat keras yang dilakukan meliputi perangkat keras yang digunakan dalam pembangunan sistem dan perangkat keras yang diperuntukan bagi komputer yang akan menggunakan aplikasi ini. Berikut ini merupakan spesifikasi perangkat keras untuk komputer dan juga webcam yang digunakan dalam pembangunan sistem: 
Tabel 4.3.1 Implementasi Perangkat Keras

\begin{tabular}{|c|c|}
\hline Perangkat Keras & Keterangan \\
\hline Komputer & 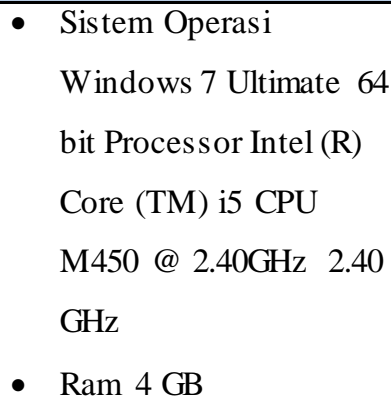 \\
\hline Webcam & - A4TECH 1080p \\
\hline
\end{tabular}

\section{Hasil Program}

Metode Viola jones merupakan sebuah metode yang paling banyak digunakan karena memilki tingkat keakurasian paling tinggi diantara metode lainnya. Hasil daripada aplikasi ini berupa peringatan yang berupa suara akan berbunyi apabila mata pengendara mobil sudah mengantuk.

Program deteksi mata mengantuk ini berbasis GUI, terdapat beberapa tombol button yang digunakan untuk mengoperasikan aplikasi ini. Pada aplikasi ini terdapat tombol scroll yang berfungsi untuk mengatur tingkatan mata biner. Setelah mengatur mata biner maka tekan tombol start untuk memulai program. Dan terdapat juga tombol keluar yang berfungsi untuk keluar dari aplikasi.

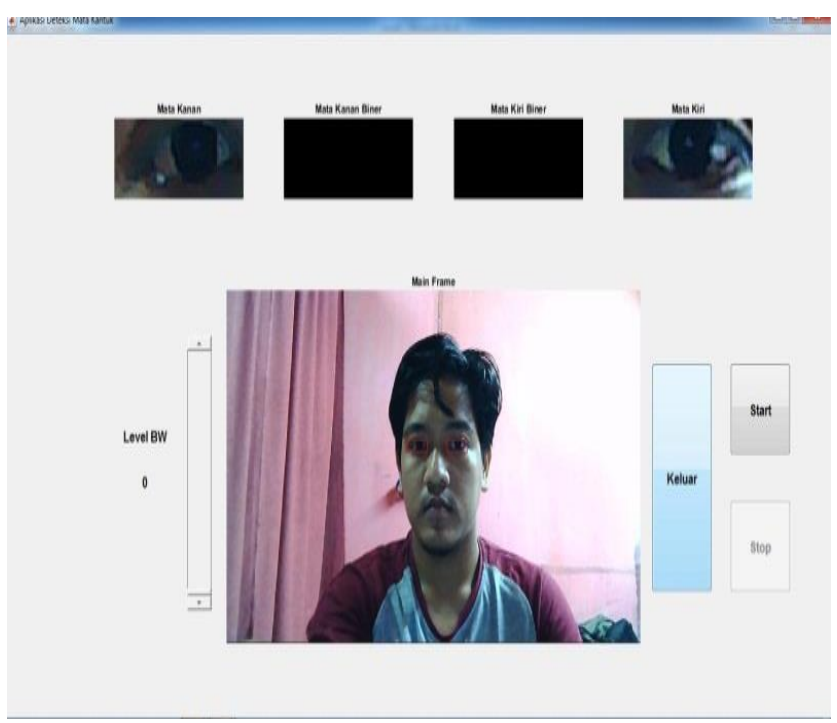

Gambar 3.1 Mendeteksi Wajah dan Mata

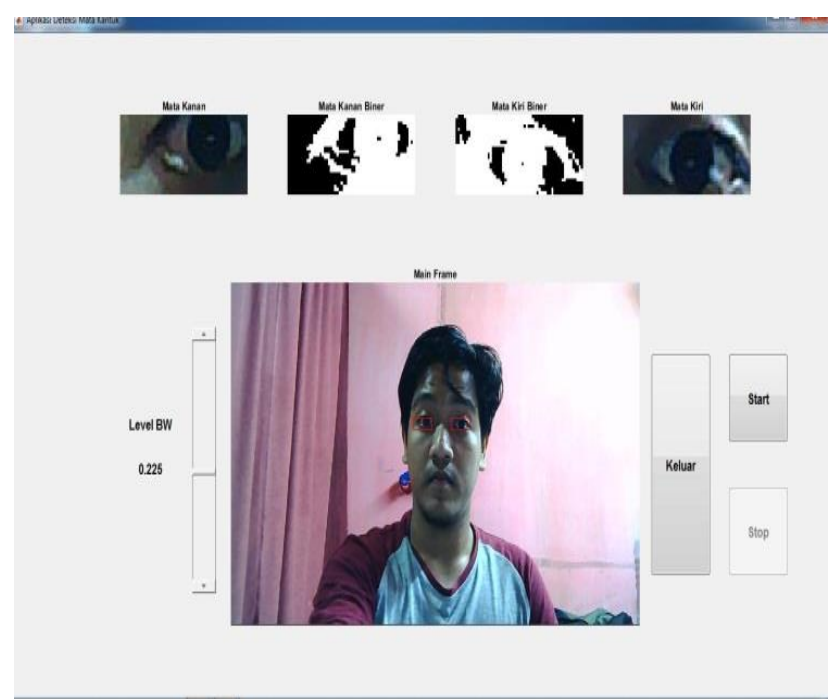

Gambar 3.2 Mendeteksi Mata Biner

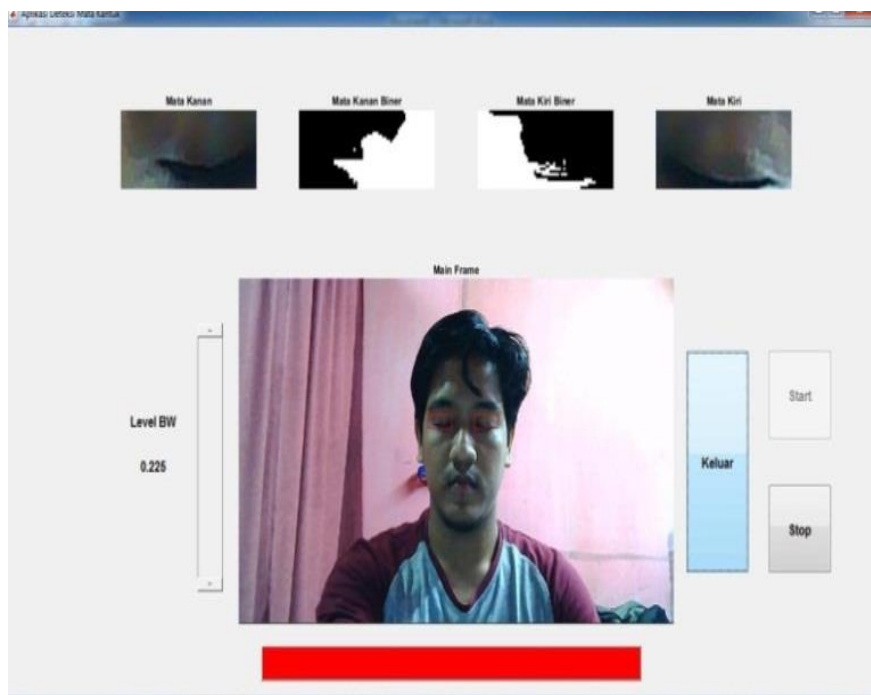

Gambar 3.3 Mendeteksi Mata tidak Megantuk

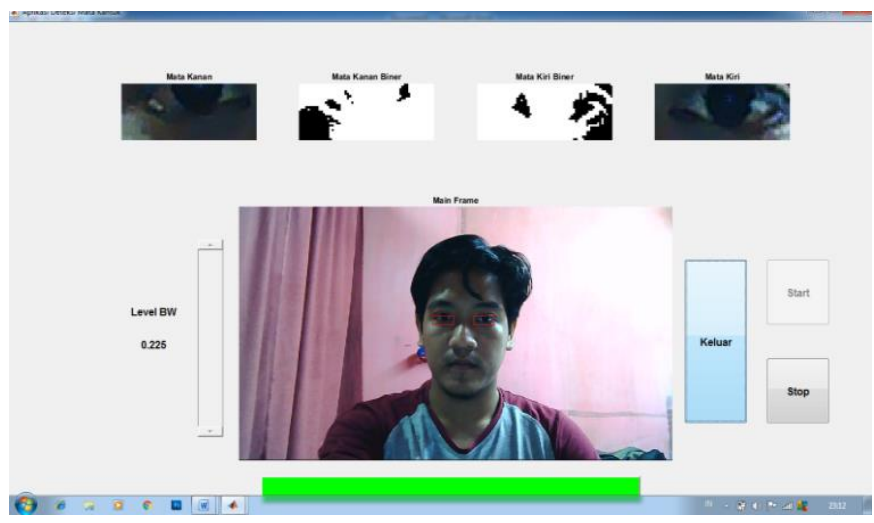

Gambar 3.5 Mata kantuk terdeteksi dan alarm berbunyi. 
Tabel 4.1 Hasil Pengujian Program

\begin{tabular}{|c|c|c|c|c|}
\hline No. & Nama & Jarak & $\begin{array}{l}\text { Level } \\
\text { Biner }\end{array}$ & Hasil Penelitian \\
\hline 1 & Kelvin Frasetia & $20 \mathrm{~cm}$ & 0.345 & $\begin{array}{c}\text { Berhasil } \\
\text { Mendeteksi }\end{array}$ \\
\hline 2 & Rahmat Maulana & $10 \mathrm{~cm}$ & 0.235 & $\begin{array}{c}\text { Berhasil } \\
\text { Mendeteksi }\end{array}$ \\
\hline 3 & $\begin{array}{c}\text { Dwiki Adtiya } \\
\text { Utama } \\
\end{array}$ & $5 \mathrm{~cm}$ & 0.13 & Tidak berhasil \\
\hline 4 & Fachrid Alhadi & $55 \mathrm{~cm}$ & 0.34 & Tidak berhasil \\
\hline 5 & $\begin{array}{c}\text { Lukas Raesmana } \\
\text { PA }\end{array}$ & $20 \mathrm{~cm}$ & 0.34 & $\begin{array}{c}\text { Berhasil } \\
\text { Mendeteksi }\end{array}$ \\
\hline 6 & Zulfa Fauzal & $10 \mathrm{~cm}$ & 0.13 & $\begin{array}{c}\text { Berhasil } \\
\text { Mendeteksi }\end{array}$ \\
\hline 7 & Haviz Fazlullah & $60 \mathrm{~cm}$ & 0.39 & Tidak berhasil \\
\hline 8 & Riki Altamba & $25 \mathrm{~cm}$ & 0.39 & $\begin{array}{c}\text { Berhasil } \\
\text { Mendeteksi }\end{array}$ \\
\hline 9 & Raza Oktavian & $25 \mathrm{~cm}$ & 0.13 & $\begin{array}{c}\text { Berhasil } \\
\text { Mendeteksi }\end{array}$ \\
\hline 10 & Feri Fadli Aiyub & $40 \mathrm{~cm}$ & 0.275 & $\begin{array}{c}\text { Berhasil } \\
\text { Mendeteksi }\end{array}$ \\
\hline
\end{tabular}

Program mata kantuk ini tidak berjalan $100 \%$ disebabkan juga mungkin dengan jarak yang membuat program tidak berjalan $100 \%$, jadi kalau jarak mata dengan webcam semakin jauh maka bukan tidak berhasil tetapi hasilnya tidak akurat.

\section{KESIMPULAN DAN SARAN}

Aplikasi mata mengantuk sangat terpengaruh oleh beberapa factor seperti kamera, semakin bagus kamera yang digunakan maka resolusi gambar yang didapat akan semakin bagus Dan kecepatan dalam mendeksi wajah maupun mata akan lebih cepat apabila menggunakan kamera yang bagus, jadi disarankan untuk supaya hasil gambar menjadi bagus saya sarankan untuk memakai kamera Output atau Webcam.

Aplikasi ini sangat rentang akan cahaya yang masok, dan pada aplikasi ini akan mengalami kendala apabila mendeteksi seseorang yang sedang menggunakan kacamata jadi di harapkan kepada kalian semua kalau ingin menggunakan aplikasi ini maka kita tidak boleh memakai kacamata atau sejenis lainnya yang menutupi bola mata kita sehingga kalau tidak ada yang mentupi bola mata kita maka akan lebih cepat mendapatkan hasil dari program ini.

Implemetasi dari pada aplikasi ini dipakai untuk pengemudi mobil pada umumnya yang mana sangat berguna untuk menghindari kecelakaan mobil yang disebabkan oleh supir mengantuk. Jadi aplikasi ini akan berguna bila dipasangkan pada mobil, terlebih mobil tersebut merupakan mobil yang melakukan perjalanan yang jauh. Jadi apabila aplikasi telah dipasang, dan pada saat pengemudi mengalami mata ngantuk (mengantuk) maka sura peringatan akan berbunyi dengan keras sehingga pengemudi tersebut bisa beristirahat sejenak.

\section{DAFTAR PUSTAKA}

[1] N. C. S. Dewi and I. N. Budiantara, "Faktor-Faktor Yang Mempengaruhi Kecelakaan di Provinsi Jawa Timur Menggunakan Regresi Nonparametrik Spline Truncated," vol. 7, no. 2, 2018.

[2] H. Fitrianti, "MODEL FAKTOR-FAKTOR BANYAKNYA KECELAKAAN LALU LINTAS PADA KENDARAAN SEPEDA MOTOR DENGAN PENDEKATAN GENERALIZED LINEAR MODEL," vol. 4, pp. 94-104, 2017.

[3] A. Y. Rahman, S. Sumpeno, and M. H. Purnomo, "Arca detection and matching using Scale Invariant Feature Transform (SIFT) method of stereo camera," vol. 2018Janua, no. July 2018, pp. 66-71, 2018.

[4] Afrizal Zein, "Pendeteksian Kantuk Secara Real Time Menggunakan Pustaka OPENCV dan DLIB PYTHON Real Time Sleepiness Detection Using OPENCV Library and PYTHON DLIB," vol. 28, no. 2, pp. 22-26, 2018.

[5] B. Tryanto, M. Nasrun, and R. A. Nugrahaeni, "DETEKSI MATA MENGANTUK PADA PENGEMUDI MOBIL," vol. 18, no. 2, pp. 321-329, 2019.

[6] Imanuddin, F. Alhadi, R. Oktafian, and A. Ihsan, "Lie Detektor With Eye Tracking Analysis and Pupil Dilation Based Video Camera," vol. 5, no. 3, pp. 6139-6145, 2018. 